\title{
AN ACCESSORY/ABERRANT LEFT INFERIOR POLAR ARTERY ARISING FROM THE AORTIC BIFURCATION
}

\author{
Sreekanth Tallapaneni, Simmi Soni, Mohammed Ismail Khan, Shahzeb Zaman, Vithala Sai Navya.
}
1. Associate Professor. Department of Anatomy, Shadan Institute of Medical Sciences Teaching Hospital \& Research Centre.
2. Associate Professor. Department of Anatomy, Dr. V.R. K. Women's Medical College Teaching Hospital \& Research Centre.
3. Final MBBS- Part II Student. Department of Anatomy, Shadan Institute of Medical Sciences Teaching Hospital \& Research Centre.
4. Final MBBS- Part I Student. Department of Anatomy, Shadan Institute of Medical Sciences Teaching Hospital \& Research Centre.
5. Second MBBS Student. Department of Anatomy, Shadan Institute of Medical Sciences Teaching Hospital \& Research Centre.

\section{CORRESPONDING AUTHOR:}

Sreekanth Tallapaneni, 10-3, 799/Vijayanagar Colony, Hyderabad, Andhra Praddesh, PIN -500057.

E-mail: anatomysreekanth18@yahoo.com

\begin{abstract}
The frequently to rarely occurring wide range of variations in the renal vasculature are considered critical issue that surgeons should have a thorough envision and appreciation of the condition. During the routine prosection hours for the preclinical MBBS students at Shadan Institute of Medical Sciences, Teaching Hospital and Research Centre, while dissecting a male cadaver revealed an interesting variation. The Main Renal Artery (MRA) was arising from the aorta about $1.8 \mathrm{~cm}$ below the Superior Mesentric Artery (SMA) extending laterally towards the hilum of the kidney. At about $1.5 \mathrm{~cm}$ below the origin of the Inferior Mesenteric Artery (IMA) from the antero lateral aspect of the Aortic Bifurcation, an aberrant renal artery measuring 4.5 $\mathrm{cm}$ in length, was seen coursing upwards, backwards and laterally \& made its portal of entry by penetrating into the medial border and extending on to the posterior surface by piercing the capsule just half $\mathrm{cm}$. above its lower pole. The ureter and the gonadal vessels were superficial to it. A thorough knowledge of the variations of renal vascular anatomy has importance in exploration and treatment of renal trauma, renal transplantation, renal artery embolization, surgery for abdominal aortic aneurysm and conservative or radical renal surgery.
\end{abstract}

KEY WORDS: (Accessory artery) (lower polar artery) (Aortic Bifurcation) (Aberrant renal artery).

INTRODUCTION: Each kidney is supplied by a renal artery which arises from abdominal aorta below the origin of superior mesenteric artery on each side. Right artery is longer than the left artery, because abdominal aorta lies on the left side of vertebral column. The renal artery divides into anterior \& posterior trunks. Anterior trunk passes in front of the renal pelvis and subdivides usually into four segmental arteries apical, upper and anterior, middle and anterior, inferior. Posterior trunk passes behind the renal pelvis and is continued as posterior segmental artery [1]. Sometimes an accessory renal artery arising from the aorta or an aberrant artery supplies upper or lower pole of the kidney without passing through the hilum. An accessory artery is the precocious origin of a segmental artery. The presence of an accessory / aberrant renal artery at the lower pole is infact a segmental vessel that is a persisted foetal vessel with an 
abnormal origin [2]. True aberrant vessels are rare except in patients with renal ectopia, with or without fusion, and in individuals with a horse shoe kidney. True aberrant renal arteries are those which may arise from common, external, internal iliac, middle sacral, testicular, inferior phrenic or superior mesenteric arteries. In $70 \%$ of cases there is a single renal artery supplying each kidney [3]. Numerous reports have appeared in the literature describing variations in renal vascular anatomy. Knowledge of the variations of renal vascular anatomy has importance in exploration and treatment of renal trauma, renal transplantation, renovascular hypertension, renal artery embolization, angioplasty, or vascular reconstruction for congenital and acquired lesions, surgery for abdominal aortic aneurysm and conservative or radical renal surgery [4].

EMBRYOLOGY: The embryological explanation of these variations has been presented and discussed by Keibel $\mathrm{F}$ and Mall FP [5]. In an $18 \mathrm{~mm}$ fetus, the developing mesonephros, metanephros, suprarenal glands and gonads are supplied by nine pairs of lateral mesonephric arteries arising from the dorsal aorta. Felix divided these pairs of arteries into three groups as follows: the $1^{\text {st }}$ and $2^{\text {nd }}$ arteries as the cranial group, the $3^{\text {rd }}$ to $5^{\text {th }}$ arteries as the middle group and $6^{\text {th }}$ to $9^{\text {th }}$ arteries as the caudal group. The middle group gives rise to renal arteries. Persistence of more than one renal arteries of the middle group results as multiple renal arteries [5]. Thus, the duplicated renal arteries in our study are a result of two persisting lateral mesonephric arteries from the middle group. Accessory renal arteries are found frequently on the left side and the range of incidence is as high as $30-35 \%$ of cases \& these arteries usually enter the upper or lower poles of the kidney [6].

MATERIALS AND METHODS: A formalin - fixed elderly male cadaver along with Routine instruments like a pair of gloves, Scalpel, Blade, Surgical forceps, Anatomical Forceps, Dissector, Metallic Scale with Calibrations were used. Kidneys are a pair of excretory organs lying over the posterior abdominal wall on either side of vertebral column retro-peritoneally. The anterior abdominal wall was dissected layer by layer. The visceral organs like liver, stomach, \& intestines were all studied in Situ and dissected out. The duodenum, pancreas and spleen were all dissected away from the abdominal cavity and the peritoneum was stripped to visualize the kidneys. The fat and the renal fascia from anterior surfaces of the left kidney were removed. At the hilum of the kidney the left renal vein was seen draining into the Inferior Vena Cava (IVC). The main renal artery of the left kidney was seen behind the main renal vein and was entering into the hilum sandwiched between vein and the renal pelvis.

OBSERVATION: The Main Renal Artery (MRA) was arising from the aorta, about $1.8 \mathrm{~cm}$ below the Superior Mesenteric Artery (SMA) which was extending laterally and horizontally towards the hilum of the left kidney. An accessory renal artery was seen arising at about $1.5 \mathrm{~cm}$ below the origin of the Inferior Mesenteric Artery (IMA) from the antero lateral aspect of the Aortic Bifurcation (Figure 1, 3\& 4), an aberrant renal artery was seen coursing upwards, backwards and laterally \& made its portal of entry by penetrating into the medial border (Figure $2,3 \& 4$ ) and extending on to the posterior surface by piercing the capsule just half $\mathrm{cm}$. above its lower pole Figure (4). The artery exhibited a fork like pattern at its termination (Figure $2 \& 4$ ). The Main Renal Artery (MRA) was arising about $1.8 \mathrm{~cm}$ below the origin of Superior Mesenteric Artery (SMA). The lower polar artery was arising $8.5 \mathrm{~cm}$ below the SMA and $1.5 \mathrm{~cm}$ below the origin of Inferior Mesenteric Artery (IMA) the lower renal polar artery was measuring about 4.5 $\mathrm{cm}$ in length. The ureter and the gonadal vessels were seen superficial to it (Figure 1, 2, 3 \& 4). 


\section{CASE REPORT}

The Main Renal vein was draining into inferior vena cava. The hilar structures showed normal horizontal and vertical disposition. The vasculature of the right kidney did not exhibit any such variation.

DISCUSSION: The credit on earliest information on aberrant renal arteries goes to EUSTACHIUS in 1552 (Graves, 1956) who recorded his findings on copperplates which of course remained obscure and unpublished for nearly 162 years [7]. However from the middle of the $19^{\text {th }}$ century cases of aberrant renal arteries have been reported in literature. In the present times due to institutionalization of dissection and noninvasive modern techniques it became possible and many cases have been reported. Young and Rohr 1995 described that one of the most commonly encountered material anomalies in the renal transplantation is the presence of lower polar renal artery, in many cases the artery can be anastomosed to the main renal artery and the main renal artery can then be anastomosed into recipient vessel. However there are cases where the lower polar artery is too distant from the main renal artery to allow an anastomosis to be performed. [8] In such cases inferior epigastric artery is used as an arterial supply which provided good flow to the lower pole of the kidney. In the present case the lower polar renal artery arose almost from the point of bifurcation of aorta. A summary of findings from Merklin and Michele (1958) who analyzed reports of almost 11,000 kidneys showed 71-85\% kidneys having one artery that supplied the entire renal parenchyma, and $6.9 \%$ of kidneys having 1 hilar artery and 1 lower polar artery arising from aorta. [9] In the present case the kidney was supplied by (hilar renal artery) \& lower polar artery, which arose from the aortic bifurcation below the origin of inferior mesenteric artery. Ronald - - Eisendrath (1920) after examination of 1237 kidneys by various investigators revealed that the occurrence of lower polars from aorta in 71 of 1237 kidneys or nearly $0.6 \%$,. Lower polars from the iliacs were found in only 6 , or $0.04 \%$, of the 1237 kidneys. [10] Inferior renal polar arteries have been implicated as an etiologic factor in a form of hydronephrosis correctable by surgery. Usually the lower polar arteries arise from the main renal artery, aorta or common iliac arteries. The range of their incidence is one in 185 kidneys. At times the inferior polar arteries are doubled i.e., one arising from aorta and the other from the renal artery. In the present case of the lower polar artery was single \& arose from antero-lateral aspect of aorta.

Bordei P et al. (2004) studied renal vascularization and reported 54 cases of double renal arteries supplying one kidney and originating from aorta. Of the 54 cases, six cases were bilateral. In about 28 cases, supplementary renal artery entered the kidney through the hilum, in 16 cases it was inferior polar, in five cases it was superior polar [11] in the present case it is an unilateral variation and the portal of entry of the lower polar artery was through the medial border extending on to the posterior substance of the kidney. Alev Kara reported in a 38 year old female cadaver the RA emerged from aorta passed behind the IVC before reaching the hilum of the kidney. The accessory renal artery emerged from the anterior lateral surface of the aorta $5.4 \mathrm{~cm}$. distal to the renal artery to reach the lower pole of the right kidney. It was $5.8 \mathrm{~cm}$. in length. [12] In the present case the lower polar artery arose from the antero-lateral accept of the aorta. The lower polar artery's origin was about $5.8 \mathrm{~cm}$. below the MRA \& $1.5 \mathrm{~cm}$ below Inferior Mesenteric Artery (IMA). The lower polar artery was $4.5 \mathrm{~cm}$. in length.

Satheesha Nayak 2008 found an extra inferior polar artery on left side. Abdominal aorta also showed a kink at the level of origin of renal arteries. [13] In the present case the lower polar artery arose from the left side of aorta but no kink was seen at the level of its origin. Dr. Neelesh Kanaskar reported right lower polar renal artery which originated below the inferior 
mesenteric artery from the lateral aspect of aorta which coursed upwards towards the lower pole of the right kidney crossing the right testicular vein [14]. The present case was a left lower polar artery was arising from the antero lateral aspect of the termination of the aorta and coursed upwards lying behind the left gonadal vessels and ureter. Carmen Sebastiaj opines that the inferior polar arteries are important because they provide vessels to the upper urinary tract. An unnoticed section of an inferior polar artery may lead to graft pyeloureteral necrosis with secondary stenosis or urinary tract leakage. When preservation of a small inferior polar artery is not feasible, the surgeon may consider anastomosing the donor renal pelvis to the recipient ureter (pyeloureteral anastomosis). [15] K Khamanarong 2004 found single hilar artery in $82 \%$, double in $17 \%$, including $7 \%$ of upper polar arteries and $3 \%$ of lower polar arteries [16]. In the present case it was the lower polar artery falling under the rare category of variation

Yakup Yesilkava, MD. reported a case of Aberrant right polar renal artery originating from the aortic bifurcation in a fifty years old woman, that was found incidentally while investigating the patient for malignant hypertension 230/160 $\mathrm{mm} \mathrm{Hg}$ before the endovascular treatment of a cerebral aneurysm. The aberrant renal artery originating from the terminal aorta at the bifurcation point supplied the lower pole of the right kidney through the renal capsule [17]. The present variation is very much similar as far as the origin is concerned. As the lower polar artery arose from the point of bifurcation of aorta, but on the left side. K S Satyapal 2001 found that out of 130 renal angiograms and 32 cadavers, kidneys showed presence of one additional renal artery in $23.2 \%$ and two additional renal arteries in $4.5 \%$. They were seen more commonly on left side $32 \%$ as compared to $23.3 \%$ on right side. [18] In the present case one additional renal artery was seen on the left side.. Albolhassan B Shakeri 2007 reported the presence of accessory renal artery bilaterally on digital subtraction angiography performed on a renal transplant donor. Two renal arteries originated from aorta on Right side. One was a normal hilar artery and second was lower polar artery. Left accessory renal artery simultaneously supplied upper and lower pole by replacing the upper / apical and lower segmental artery. Main renal artery divided in to anterior and posterior segmental arteries [19]. In the present case the lower polar artery showed fork like pattern at its termination. In the era of machine vision pre operative assessment of the hilar structures is of great importance to the operating surgeons.

CONCLUSION: The vasculature develops through haemo-dynamically induced modeling and remodeling of numerous primitive vascular precursors. It has been shown that some of these anomalies have a genetic basis and in others abnormal embryonic or environmental factors contribute to the pathogenesis. Were the health care personnel to remain unaware of the body's prenatal progress towards maturity they would be baffled by every example of departure from the archetypal pattern or supposedly constant anatomic form. In my view "VARIANT ANATOMY ILLUMINATES EMBRYOLOGY". It has been repeatedly stated in the literature that the modern text book descriptions are accurate or hold in only about $50-70 \%$ of individuals. From the standpoint of utilization of anatomic information in radiological, surgical and clinical setting is undoubtedly without being familiar with the frequently to rarely occurring vascular abnormalities. Latest investigations such as ultra-sonography, computerized Axial Tomography, Angiography, Arterio-graphy and Various other specific imaging modalities are in use to detect all the different types of vascular anatomy which can be indispensable in exploration and treatment of renal trauma, renal transplantation, renal artery embolization, surgery for abdominal aortic aneurysm and conservative or radical renal surgery. 
ACKNOWLEDGEMENTS: Thanks to S.T Verma for DTP \& J George William Librarian Shadan Institute of Medical Sciences for their extensive support in the typing of the manuscript.

Thanks to all the students taught by me so far for their support and encouragement extended.

\section{REFERENCES:}

1. William PL, Bannister LH, Berry MM, Collins P, Dysen M, Dusek JE et al. Gray's Anatomy: The anatomical basis of Medicine and Surgery, 38 $8^{\text {th }}$ edition. New York : Churchill Livingstone; 1995. cardiovascular system $\mathrm{Ch}-10 \mathrm{Pg}-1547$.

2. R.M.H. Mcminn. Last's Anatomy: Regional and Applied, $8^{\text {th }}$ Revised Edition. Edinburgh: Churchill Livingstone; 1990. Ch - 5, Pg - 370-372.

3. Standring S. Gray's Anatomy. The Anatomical Basis of Clinical Practice. 39th Ed. London, Elseiver Churchill Livingstone Publishers. 2005; 1274-1275.

4. Nathan H, Glezer I. Right and left accessory renal arteries arising from a common trunk associated with unrotated kidneys. J Urol. 1984; 132; 7 - 9.

5. Keibel F Mall FP (eds), Manual of human embryology, Vol. 2, J.B. Lippincott, Philadelphia, 1912, 820-825.

6. Singh G, NG YK, Bay BH, Bilateral accessory renal arteries associated with some anomalies of the ovarian arteries: a case study, Clin Anat, 1998, 11(6): 417-420.

7. Eustachius B (1552) Cited by Graves. F.J. (1956). The aberrant arteries J. of Anat. 90 : 553-558.

8. Young and Rohr - 1995 Use of inferior epigastric artery to rec/Vascularise the lower pole renal artery in renal transplant American Jr of Anat 185-187.

9. Merklin R.J \& Michele, N.A (1958) The variant renal and supra renal blood supply. J. Internat. Coll. Surgeons. 29:41.

10. Illustrated Encyclopedia of Human Anatomic Variation: Opus II: Cardiovascular System:Arteries:Abdomen.http://www.anatomyatlases.org/AnatomicVariants/Cardiov ascular/Text/Arteries/Renal.shtml

11. Bordei P, Sapte E, Iliescu D, Double renal arteries originating from the aorta, Surg Radiol Anat, 2004, 26(6): 474-479.

12. Alev Kara. Zeliha Kurtoglu. Izzet Oguz. A Hakan Ozturk. Deniz Uzmansel. Department of anatomy, Faculty of Medicine Mersin University. 33169 Mersin - Trukey. Two Accessory Renal Arteries with Histological Properties. Short Report. Turk J Med Sci: 36 (2006) 133 $-138$.

13. The Internet Journal of Biological Anthropology, Internet Scientific Publications LLC, 23 Rippling Creek Drive. Sugar Land, Texas 77479, USA. Presence of accessory renal artery and kinking of aorta due to abnormal origin of renal arteries. volume 1(2). USA: The Internet Journal of Biological Anthropology; 2008. p

14. Dr. Neelesh Kanaskar, Dr. Vaishali Paranjape, Dr. Jyoti Kuulkarni, Sapna Shevade, Department of Anatomy, Dr. D.Y.Patil Medical College/Dr. D.Y.Patil University, Pune, India. IOSR Journal of Dental and Medical Sciences (JDMS), ISSN: 2279-0853, ISBN: 2279-0861. Volume 1, Issue 5 (Sep-Oct. 2012), PP 17-20.

15. Carmen Sebasttia, MD, Liuis Peri, Md, Rafael Salvador, MD, Laura Bunesch, MD, Ignacio Revuelta, MD Antonio Alcaraz, MD and Carlos Nicolau, MD 1 From the Departments of Radiology (C.s., R.s., L.B., C.N.,), Urology (L.P., A.A.), and Nephrology (I.R), Hospital Clinic, 
Villarroel 170, 08030 Barcelona, Spain. Multidetector CT of Living Renal Donors: Lessons Learned from Surgeons.

16. Khamanarong K, Prachaney P, utraravichien A, Tong-Un T, Shripaoraya Lx. Anatomy of Renal arterial supply. Clinical anatomy 2004; 17(4): 334 - 336.

17. Yakup Yesilkava MD. Hacellepe University Faculty of Medicine Department of Radiology Sihhiye Ankara 06100. Turkey. Aberrant right polar renal artery originating from bifurcation. International Journal of Anatomical Variations (2012) 5: 25 - 26.

18. K. S. Satyapal, A.A Haffejee, B. Singh, L.Ramsaroop, J.V.Robbsand, J.M. Kalideen. Additional Renal Arteries Incidence And Morphometry, Surgical And Radiologic Anatomy, Vol. 23m Bynber 1 (2001), 33 - 38.

19. Abolhassan B, Shakeri R, R. Shane Tubbs, Mohammadali M., Shoja, Parham Pezeshk, Rahim M. Farahani, Amir A. Khaki, Fatemeh Ezzati and Farshad Seyednejad, Bipolar Supernumerary Renal Artery, Surgical And Radiological Anatomy, Anatomic Variations, Vol 29, Number 1 (2007), 89 - 92.

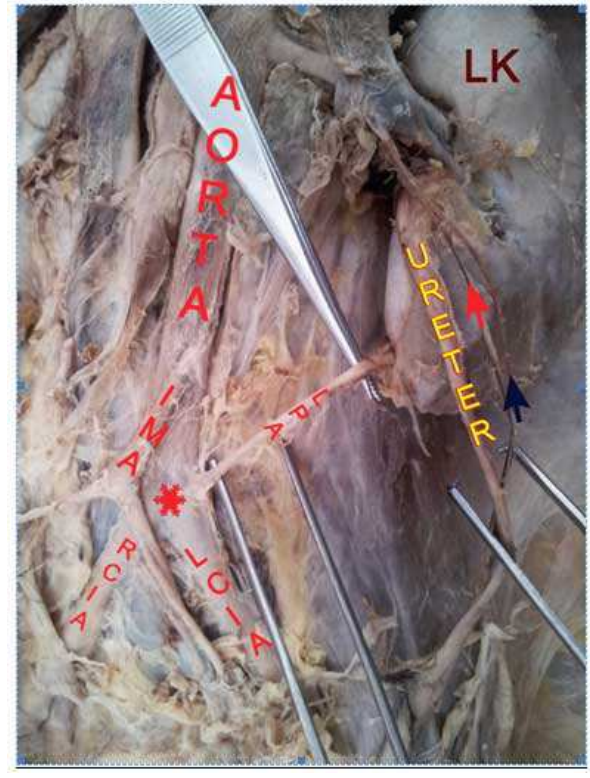

FIGURE .: 1 ANTERIOR VIEW OF THE DISSECTION OF THE LEFT KIDNEY LK - LEFT KIDNEY, * ASTERICK INDICATING POINT OF AORTIC BIFURCATION

MRA - MAIN RENAL ARTERY, LPA - LOWER POLAR AORTIC ARTERY, IMA - INFERIOR MESENTERIC ARTERY, IVC - INFERIOR VENA CAVA, MRV - MAIN RENAL VEIN LCIA - LEFT COMMON ILIAC ARTERY, RCIA - RIGHT COMMON ILIAC ARTERY

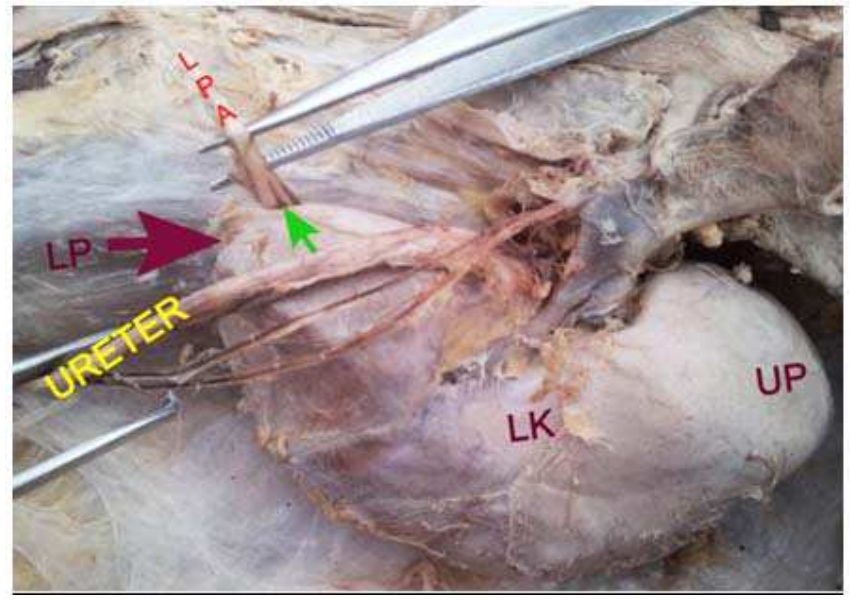

FIGURE .: 2 SUPERIOR VIEW OF THE DISSECTION OF THE LEFT KIDNEY LK - LEFT KIDNEY, UP - UPPER POLE, LP - LOWER POLE \{INDICATED BY BROWN ARROW\} LPA - LOWER POLAR ARTERY, GREEN ARROW- INDICATES THE POINT OF PENETRATION OF THE LPA ALONG THE MEDIAL BORDER OF THE LEFT KIDNEY 


\section{CASE REPORT}

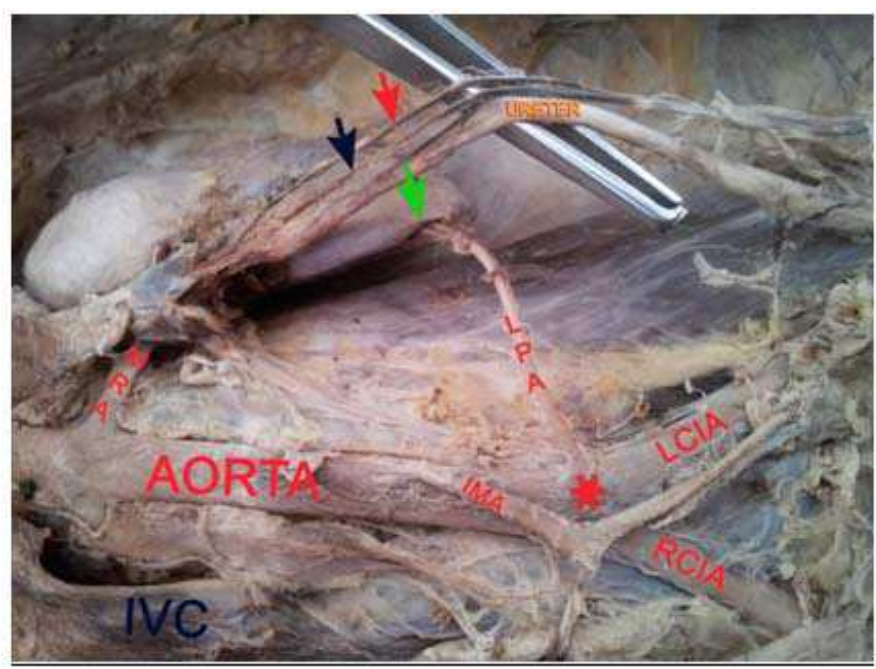

FIGURE .: 3 RIGHT LATERAL VIEW OF THE DISSECTION OF THE LEFT KIDNEY IMA - INFERIOR MESENTERIC ARTERY, MRA - MAIN RENAL ARTERY

* ASTERICK - INDICATING THE POINT OF AORTIC BIFURCATION, LCIA - LEFT COMMON ILIAC ARTERY, RCIA - RIGHT COMMON ILIAC ARTERY, GREEN ARROW - INDICATING THE POINT OF PENETRANCE OF THE MEDIAL BORDER BY THE LPA.

THE RED BLUE ARROWS - INDICATE THE GONADAL VESSELS LIFTED UP BY THE FORCEPS ALONGWITH THE URETER

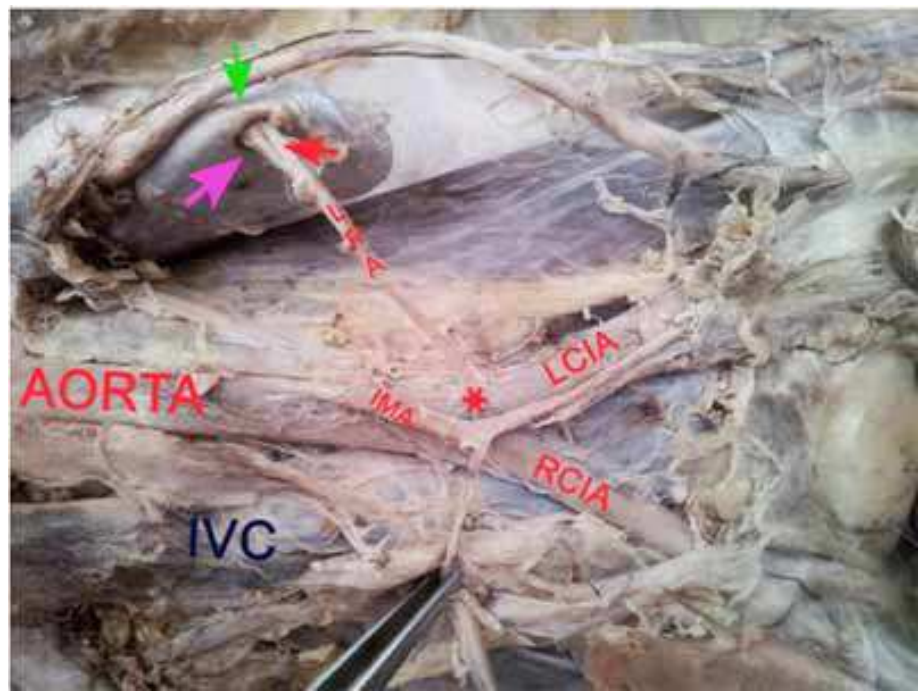

FIGURE .: 4 RIGHT LATERAL VIEW OF THE DISSECTION OF THE LEFT KIDNEY. THE PINK ARROW- INDICATES THE POSTERIOR SURFACE OF THE LEFT KIDNEY. THE RED ARROW - INDICATES THE TERMINATION OF LPA IN THE FORM OF A FORK

THE GREEN ARROW - INDICATES THE MEDIAL BORDER LCIA - LEFT COMMON ILIAC ARTERY, RCIA - RIGHT COMMON ILIAC ARTERY, *ASTERICK- INDICATING THE POINT OF AORTIC BIFURCATION 